
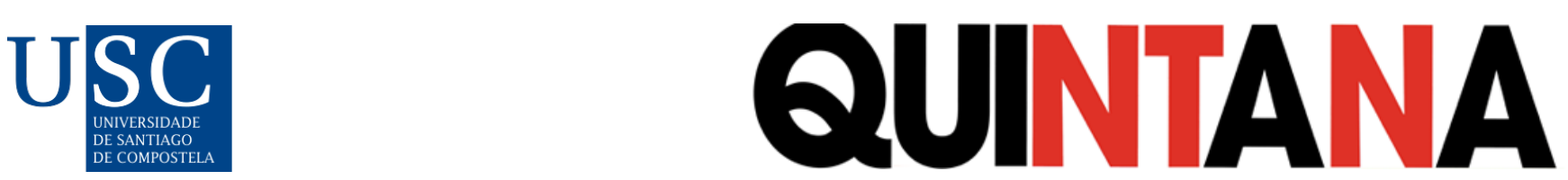

Quintana: revista do Departamento de Historia da Arte, (20), 2021. ISSN-e: 2340-0005

https://doi.org/10.15304/quintana.20.6434

Colaboracións

\title{
LUIS DE ACOSTA, PLATERO, Y PEDRO ROLDÁN, ESCULTOR. SOBRE LA AMISTAD QUE LES UNIÓ Y EN RELACIÓN CON UN BELÉN QUE COMPARTIERON
}

LUIS DE ACOSTA, SILVERSMITH, AND PEDRO ROLDÁN, SCULPTOR. ON THE FRIENDSHIP THAT UNITED THEM AND IN RELATION TO A NATIVITY SCENE THAT THEY SHARED

\section{Fernando Quiles (iD)}

Universidad Pablo de Olavide, España

fquigar@upo.es

Recibido: 03/12/2019; Aceptado: 08/02/2020

\section{Resumen}

Siguen unas líneas que nos ponen en antecedentes sobre la vida y obras de un platero que trabajó para la Catedral de Sevilla en la segunda mitad del XVII. No tuvo una obra destacada, pero sí una trayectoria que le vinculó con los más importantes artífices de la época, especialmente con Pedro Roldán, de quien llegó a tener un Nacimiento. Esto último nos permite situar a Roldán en un nuevo ámbito creativo, en el que su hija Luisa destacó, con lo que podríamos además establecer el vínculo entre maestro y discípula en ese nuevo escenario creativo.

Palabras clave: Luis de Acosta; Pedro Roldán; platería barroca; barroco sevillano; belén sevillano.

\begin{abstract}
The paper describes the life and works of a silversmith who worked for the Cathedral of Seville in the second half of the XVIIth c. His production was not outstanding, but he did have a career running in parallel with the most important architects of the time, especially with Pedro Roldán, with whom he authored a Nativity scene. The latter allows us to place Roldán in a new creative field, in which his daughter Luisa stood out, with which we could also establish the link between teacher and disciple in that new creative scenario.
\end{abstract}

Keywords: Luis de Acosta; Pedro Roldán; baroque silverware; Sevillian baroque; Sevillian nativity scene.

Con seguridad el mejor relato de la vida de un artista se puede hacer con el conocimiento de su círculo de amistades. Y más aún en el caso de creadores de reconocida valía, por el hecho de ser más abundante la información relativa a su vida y obras. Es lo que ocurre con Pedro Roldán, cuyo prestigio es indiscutible, y aunque es mucho lo escrito sobre su arte y personalidad, habiéndose incluso reconstruido en parte su entorno familiar, aunque sigue a medio hacer el entramado de amistades. De entre las que rescato un platero capitular Luis de Acosta. Y a propósito de ello quiero ofrecer un indicio de la actividad, nada conocida, de Roldán como belenista. 


\section{LUIS DE ACOSTA, UN PLATERO SINGULAR}

Aun cuando los documentos y referencias históricas que traigo a colación en este estudio pertenecen a Luis de Acosta, la noticia más relevante tiene que ver con el descubrimiento de la faceta de Pedro Roldán como autor de escultura ligera. A continuación glosaré el testamento de Acosta, datado el 26 de agosto de 1674, en el que el platero pone en orden sus asuntos, dejando entrever su relación con Roldán, del que poseyó un Nacimiento. Esta noticia además despeja ciertas dudas sobre la formación de la más importante belenista del barroco hispano, Luisa Roldán, y de paso ratifica la importancia del arte napolitano en Sevilla, adelantando incluso la cronología que teníamos de su presencia en el medio. De manera que podríamos reivindicar el magisterio del padre sobre la hija, siendo el espejo en el que la joven artista se miró a la hora de desarrollar su carrera como escultora de belenes e incluso para el conjunto de su obra, tan marcada por esa manera de hacer en pequeño formato ${ }^{1}$. Y de otro lado, repensar la influencia del arte meridional italiano en la configuración de los modelos del arte menudo sevillano.

El citado testamento nos brinda la oportunidad de conocer mejor la vida y milagros de tan singular orfebre. En principio nos descubre el nombre de sus padres, Joana de Rivas y Pedro de Acosta. Éste podría ser platero también ${ }^{2}$. Al menos circula información sobre un artífice con ese nombre y activo años antes. Aun cuando se dice en el documento que padre y madre eran naturales de Sevilla, cabría pensar en la ascendencia portuguesa y en la apertura de una nueva vía de conocimiento sobre las relaciones artísticas con el ámbito lusitano, vínculo que bien podría también establecerse en relación con la escultura menuda ${ }^{3}$.

Fija Acosta como última voluntad su deseo de ser enterrado en la cripta del Sagrario, tras un funeral con acompañamiento de los hermanos de la Santa Caridad. Vínculos, por demás, que le sitúan en un medio en el que se encuentra con algunos de los artistas que a continuación mencionaremos.

De su generosa actitud da cuenta, un legado a la sacramental del Sagrario, compuesto de "dos ángeles de madera estofados y dorados con dos incensarios y dos nabetas de plata en las manos que son los mismos que a lleuado la custodia de la dha hermandad" ${ }^{4}$. Pero más ejemplar testimonio es el dinero que dejó a beneficio de doncellas pobres, para que tomaran estado 5 .

Sigue desgranando sus últimas voluntades sin olvidar a sus compañeros de oficio. Puso en manos del canónigo León y Ledesma una partida de dinero para aprovechamiento de la menor Luisa de Acosta, hija del platero Bernardo Andino, difunto ${ }^{6}$. Más aún: reconoció que guardaba 1076 reales que le había entregado el licenciado don Joan de Olivar, abogado que fue de la Real Audiencia y Veinticuatro, como pertenecientes a los hermanos Casilda, Serafina y Laureano del Rosal ${ }^{7}$. Este último acabó ingresando en el taller de Acosta, para acabar siendo maestro platero por estas fechas.

Su bonhomía no acaba con la protección de los menores referidos, también se manifestó casando a su criada, Ana de la Concepción, mayor de 16 años y huérfana, con Bernardo Andino, también

platero de mazonería. ${ }^{8}$ Y un lustro más tarde se ocupó de la dote de doña Petronila de Baeza, hija de Pedro de Baeza y de doña María Zorrilla, "a la que le tiene voluntad" por haber estado en su casa más de tres años. Ascendía a 481 ducados que otorgaba a beneficio de Pedro de Cuervas, platero de oro, como probablemente lo fue el difunto suegro 9 .

Su círculo se amplía con quienes le acompañaban en el taller, aprendices y oficiales. De la vitalidad del obrador, habida cuenta de los encargos que recibe, sobre todo a partir de su ingreso 
en la catedral, da muestra un contrato de aprendizaje entre otras, firmado en agosto de 1669 con Marcos Díaz, maestro cerrajero, para instruir a su hijo Pedro, de 15 años, durante seis años. El documento suscrito por las partes especifica que el maestro "le a de enseñar el dho arte de platero de maconeria, artes y secretos dél". 10

\section{Platero de la catedral y veedor del oficio}

Luis de Acosta fue platero de la catedral sevillana en el periodo que va de 1665 a 1680 , entre los ejercicios de Mateo Gutiérrez y Diego de Gámez ${ }^{11}$. El nombramiento tuvo una novedad con respecto al de sus antecesores, pues aun cuando le confirieron "los mismos honores" que a ellos, no tenía asignado salario, de manera que los ingresos del quedaron a expensas de la tarea realizada: "que las obras que hiciere se le paguen en la conformidad q ajustaren los dhos señores Oficiales de Fabrica". ${ }^{12}$ A buen seguro este cambio en la gestión económica de la catedral condicionó el trabajo de taller, que hubo de seguir atento a la demanda externa, si bien es cierto que el sistema pudo estimular la creatividad en la búsqueda de nuevos encargos catedralicios, colegiados e indivualizados. Aun cuando no son muchas las obras de mazonería que se le pueden atribuir ${ }^{13}$, aparte de las innumerables reparaciones y obras menores, no dejan de ser significativas tres piezas que aún hoy se conservan. En 1671 hizo el basamento del sagrario de la capilla real ${ }^{14}$, que en pocos años fue renovado por Juan Laureano de Pina, así como otras dos obras que se hicieron por encargo del canónigo de la Puente Verástegui: la elaboración de dos blandones para completar el conjunto de los Zapata $(1671)^{15}$ y el trono de octavas del Corpus $(1672)^{16}$. Este último viene a zanjar un largo debate sobre la conformación del monumento en plata con el que se habría de celebrar el Corpus Christi, a raíz del breve pontificio de 1662. Con la concurrencia del artífice y con el apoyo decidido del canónigo de la Puente, se decidió finalmente hacer un "trono" ${ }^{17}$.

Queda fuera de estas encomiendas catedralicias la labor que desarrolló, también en el propio templo, pero a expensas de otro patrono, Gonzalo Nunes de Sepúlveda. Una obra que cronológicamente se sitúa al margen del periodo de vigencia en su cargo: una corona con diadema, de plata dorada con esmaltes, que le abonarían Andrés de Arriola e Isidro Blázquez, en diciembre de $1655^{18}$. Que se conozca es la primera obra conocida y sin duda una buena carta de presentación ante el cuerpo capitular ${ }^{19}$. Este hecho revela, además, el reconocimiento público del orfebre, no en vano, todos los artífices implicados en la reforma de la capilla de Nunes de Sepúlveda gozaban de la mayor reputación ${ }^{20}$.

Más luz proyectan las fuentes sobre la dimensión artística de Acosta. No sólo mantuvo tratos con importantes patronos, sino que también ocupó cargos de responsabilidad al frente del gremio de plateros, llegando a ser, en la década de los sesenta, veedor ${ }^{21}$. Desde esa posición y en compañía de los demás representantes de los artistas plateros de oro y plata de la hermandad de san Eloy, suscribe a principios de 1660 un poder para que por tres años Gaspar de los Reyes pueda usar el oficio de marcador de pesos y marcas de la ciudad y su tierra ${ }^{22}$. También se le ha relacionado con una de las ilustraciones del Libro de exámenes de plateros, que reproduce uno de los blandones labrados para la seo ${ }^{23}$.

El gremio favoreció estas actitudes solidarias, en tanto que el éxito profesional le permitió acrecentar su círculo de amistades. Además, el ingreso en el medio capitular fue su carta de 
presentación ante las élites locales y los más acreditados artistas del momento. Evidentemente, dentro de la platería se localiza el mayor grupo de amistades de Acosta. Aparte del grupo que le acompañó en la dirección del gremio al tiempo que fue veedor, otros artífices se relacionan con él, como Andrés de León, a quien proveyó de plata para uno de sus trabajos ${ }^{24}$; o Manuel de Lara, inquilino de una de sus propiedades en la calle Batihojas ${ }^{25}$. Curiosamente, no hay indicios sobre contactos entre Acosta y Juan Laureano de Pina, quien en la década de los setenta está trabajando para la capilla real en importantes obras de platería. Y con respecto al cabildo, a excepción de Francisco de la Puente, no sabemos de más tratos con otros miembros del mismo. En el caso del citado canónigo, ya se adelantó que se trataba de la realización de unos blandones, de acuerdo con una carta de obligación y la supervisión directa del arcediano Francisco Ponce ${ }^{26}$. Llama la atención que la provisión de plata corrió de cuenta de Juan de Ochoa, a quien se sitúa en el entorno de Gonzalo Nunes de Sepúlveda y de sus albaceas testamentarios, vascos y portugueses con tratos mercantiles muy diversificados.

Cabe pensar que Acosta tuvo más que una muda aceptación del modelo en madera de Bernardo Simón de Pineda, cuando se le encomendó en 1672 realizar la urna para la mesa de los Ángeles de las Octavas del Corpus ${ }^{27}$. Al respecto, hay que considerar la inmersión profunda en el medio artístico sevillano, entre los más descollantes creadores del momento. Pineda es uno de ellos, al igual que Roldán y tal vez Valdés Leal. Estos tres maestros que coincidieron en diversas empresas artísticas de la mayor importancia, ejercieron en cierto modo una notable influencia en la producción de los talleres locales.

Por el hecho de encajar la corona de plata que hizo a la Inmaculada de la capilla de san Pablo, también hubo de coincidir en algún momento con Alonso Martínez, quizás Martín Moreno, autor del retablo y, por qué no, otros artífices que intervinieron en la reforma del citado recinto. Coincidió también con Juan Pérez Crespo, colaborador de Roldán ${ }^{28}$. Y a través de ellos con el pintor y dorador Alonso Sánchez.

\section{Bienes artísticos de su propiedad}

Volviendo sobre el testamento voy a adentrarme en lo posible en su hogar, a la búsqueda de nuevos indicios sobre su obra y su modus vivendi ${ }^{29}$. Se alude, por ejemplo, a los objetos de plata "de altar", que bien podrían haber sido hecho por el propio artífice:

"Prim ${ }^{\text {te }}$ ocho remates y quatro jaras y quatro candeleros dos arañas y una cruz todo de plata que todo pessa treinta marcos". También: "quatro remates de filigrana y siete azafates de filigrana y seis candeleros seis macetitas cuatro canastos dos cofres quatro remates dos jarros vn bufete quatro ramos y otras piezas..." ${ }^{30}$

Saliendo del obrador para recorrer otras estancias de la casa nos encontramos algunos detalles bien interesantes, que ilustran tanto el nivel su fortuna, como sus gustos personales.

Llama la atención el conjunto de obras de arte que se reparten por las estancias, tal como relaciona el escribano y figura en el apéndice. Un único nombre aparece mencionado en dicho repertorio pictórico, Herrera, a propósito de dos láminas, una de la Concepción y otra de San Antonio, ambas con cristales y guarnición de plata. Precisamente, hoy conocemos en el haber del pintor una interesante versión grabada de la Inmaculada, que bien pudiera ser la que Acosta tuviera 
en su hogar ${ }^{31}$. No menos interesantes e ilustrativas de la sensibilidad artística del platero son algunas otras de las láminas relacionadas en el documento, entre ellas dos con reliquias y cuatro más en alabastro, además de otras tantas en cobre.

Por lo demás, tiene una nutrida colección de pintura religiosa, de entre la que llamo la atención sobre las representaciones de "vna custodia" o "la Virgen del antigua". También constituyen piezas notorias las dos "prespectiuas", que el escribano agrupa con tres "países". La presencia en esta galería de "vn quadro en que estan las armas de la Yglesia", testimonia el vínculo del artíice con el cabildo, más allá de haber cuidado de su plata durante una década. Ello unido a la tenencia de los "doce quadros de angeles con las ynsinias de la pacion", una de tantas series situadas en la órbita de Zurbarán, contribuye aún más situarlo en el medio sevillano. ${ }^{32}$

\section{El altar de la casa y la escultura}

Aparte de la nutrida colección pictórica de la que se han entrasacado arriba algunas piezas, hay que significar la presencia, en el que podía ser un oratorio, de un importante conjunto escultórico, que confirma la sensibilidad que provoca en el platero este arte.

El "altar" lo presidía un Crucifijo sobre peana sostenida por cinco ángeles volanderos. Tenía por acompañamiento dos esculturas del Niño Jesús y del Bautista, cada una con su banderola, y otras dos menores (de una tercia de alto) de San Fernando y San Luis. Remataban el altar dos águilas, en tanto que en el basamento se situaban ocho santos de medio relieve en plata. Se repartían por el altar diversos relicarios y posiblemente a los flancos otros dos altares pequeños de la Virgen y de San José. Todo ello decorado con macetas de flores de raso, talco y piedra.

En la capilla había, además, un agnus de azabache con reliquias, tres frontalitos de carey, piedra y plata y una interesante composición escultórica con dos ángeles tocando el órgano, que podría ser de Roldán, como otros dos con sus respectivas cornucopias.

\section{PEDRO ROLDÁN BELENISTA}

\section{Los nacimientos de Acosta}

Concluyo este paseo por el hogar de Acosta con otro conjunto escultórico singular. Posiblemente lo más interesante que guarda el platero en su casa, tanto por la dimensión artística del mismo como por la identidad de uno de sus autores. Me estoy refiriendo a tres "nacimientos", uno de ellos obra de Pedro Roldán. En la lectura antecedente pasé por alto un pasaje en el que se alude a los "setenta y seis marcos de plata labrada pertenecientes al nacim ${ }^{\text {to }}$ que yo acostumbrado a poner en mi cassa que se compone de lamparas $/ /{ }^{582 \mathrm{r}}$ yncençarios candeleros penicanos [sic] bufetillos pomos arañas y santitos todo de plata y otras muchas menudencias." ${ }^{33}$ Un impresionante exorno decorativo en plata, probablemente realizado por el propio Acosta con matriz roldanesca. Da idea, además, de la importancia de esta "conducta" religiosa perfeccionada con una práctica artística, a lo que el escribano alude como "poner el nacimiento", lo que tres siglos y medio después sigue haciéndose. 
El hecho de que existan tres nacimientos separados y no uno recompuesto con piezas del resto, permite pensar en una actitud conservadora, al conferirle a estas obras menudas un valor tanto material como seguramente afectivo. No obstante, la conjunción de piezas de madera con otras de barro en el caso de uno de los Nacimientos, el que se atribuye a Blas Muñoz, permite pensar en la confluencia de técnicas por necesidades operativas y el sostenimiento de la narración global con el cuidado de los detalles.

El más grande, el roldanesco, tenía escenografía propia. Sobre el mismo se colocaba "un sol de rayos y en medio el padre eterno", de tres cuartas de diámetro. En el portal se situaban, además de la Sagrada Familia y "un pastor viejo", doce angelitos "voladores" y cuatro más pequeños. Por lo que respecta al cortejo de los Magos estaba integrado por los Reyes a caballo, las figuras de "aposentador y trompeteros en sus cauallos", así como "ocho criados para los reyes con sus libreas", con "sus acemilas con sus cofres de carey con sus cubiertas de terciopelo y puntas de plata", más "tres criados de las azemilas", uno de ellos de barro. En este párrafo se citan otras piezas que no necesariamente acompañan a los reyes, pero sí forman parte del aparato narrativo del nacimiento. Aparte de los seis pastorcitos, "un negro y una negra" y "dos matachines", nueve ángeles, uno "de la gloria" y cuatro "con instrumentos". Todas y cada una de estas figurillas, de madera dorada y estofada, como de a tercia de alto, eran de mano de Roldán.

El otro nacimiento tenía "su portal de madera", en que se alojaban "una ymagen [de la Virgen] sentada con el niño en brazos y San Joseph con un cayado". Todo de madera dorada y estofada, al igual que los "tres reyes y otros dos de a cauallo". También de madera son los "diez y ocho pastores y pastoras y de diferentes trages pintados", así como "una dozena de obejas... de todas echuras". Todo lo dicho "de mano de Blas Muños". En lo demás se conjuga la madera con el barro cocido. De este material eran las "diez y seis obejas... siete puercos y una parida", aunque de madera eran los "quatro toros". No podía faltar el escenario, en concreto "una ciudad de madera de vara y media de largo, una choza y pedreria por de dentro, una torre de madera de echura de la Santa yglesia estofada y dorada con su jiraldillo y canpanas de plata". También conservaba la estructura sobre la que se montaba el nacimiento, compuesta de "ocho bancos y veinte tablas" y un fondo de escena conformado como "un lanzo [¿lienzo?] quadrado pintado el cielo y de cabezas de serafines que serbia para el cielo del nacim ${ }^{\text {to }} \mathrm{y}$ otros dos lienzos de a tres varas cada vna semejantes al de arriba".

Por último, el tercero de los nacimientos se reducía al portal, "con quatro pilares y techo, todo dorado y estofado", con el grupo familiar esculpido, llevando la Virgen el Niño en sus brazos. Llama la atención de que este conjunto se guardaba en una caja con tapas pintadas con figuras de santos. Ello induce a pensar de que se trataba de un nacimiento "viajero".

No es la primera vez que se asocia a Pedro Roldán con el género belenista. Algunos especialistas en el arte roldanesco, especialmente el de Luisa, han reparado en ciertos detalles que podrían relacionar con el taller paterno algunos de los belenes sevillanos, como el que se guarda en Santa María de Jesús y perteneció a Santa Clara ${ }^{34}$. Del mismo modo que se considera la trascendencia del maestro en la formación de la discípula dentro de esta materia, por el mero hecho de ser el cabeza de taller ${ }^{35}$. 


\section{Antecedentes sevillanos}

El belén constituyó un capítulo destacado en la historia de la imaginería, aunque su progresiva desaparición dificulta el adecuado análisis. Cabe utilizar los restos conservados más o menos completos, pocos del taller de Roldán y en su mayor parte más tardíos. La tradición se mantuvo y aun en el siglo XVIII gozó de mayor popularidad, con la llegada plena del presepe napolitano ${ }^{36}$. Las fuentes siguen siendo parcas en información, pero alguna noticia más se ha podido rescatar de entre los apretados legajos notariales. He ahí que el trianero Rodrigo Ortiz poseía, en 1708, "vn nacimiento grande que se compone de dibersas hechuras de barro y madera, como ciudades y palacios y otras casas"37.

Conocíamos la importancia del barro como materia prima de los escultores del XVII y sobre todo el XVIII. En esta segunda centuria, cuando los debates profesionales estaban a la orden del día, nos encontramos un caso singular y a la vez representativo, a propósito de la contratación por parte del cabildo catedralicio de quien iba a ocupar la plaza vacante de peón cantero. En la elección entre Esteban de la Cuesta y Domingo Grazeli, quedó descartado el segundo por el hecho de que "no sabia perfectamente de dho arte, y lo que ejercia mas en el era de hechuras y figuras de barro". ${ }^{38}$ Incluso los hubo especializados, como reconocen incluso en el título que ostentaron. Bien es verdad que el barro es materia prima de los talleres ceramistas principalmente trianeros, lo que motiva que haya artesanos, como Juan del Castillo, vecino de la collación, que adopten títulos como el de "maestro del barro" 39 . Sin olvidar la llegada masiva, tal como se puede apreciar en las fuentes, de barros de las Indias.

Otros, en cambio, se dedicaron a la manipulación de la pasta de madera, en otra especialización que tuvo un amplio registro. De la versatilidad de esta materia da prueba el hecho de que igualmente servía para la concreción de imágenes procesionales como obras de carácter efímero, tales como los monumentos del Corpus. Traigamos a colación cómo para la celebración de 1652 fueron contratados los servicios del maestro Gerónimo López, "maestro de hacer obras de pasta", para "sacar la bispera y dia de dha fiesta del corpus deste año de mil y seisçientos y çinquenta y dos y su otaba la dansa de los Jigantes y tarasca y mojarrillas". Esta competencia del artífice de pasta tiene que ver con sus destrezas profesionales, puesto que todas esas figuras festivas hubieron de labrarse en pasta ${ }^{40}$

Llama la atención que algunos especialistas, influenciados posiblemente por la popularidad del presepe italiano entre las élites locales, optaran por la terracota, después de haber sido consumados maestros en el trabajo en madera ${ }^{41}$. Es posible que haya que considerar una conexión del arte español con el italiano en una fecha indeterminada, tomando carta de naturaleza en la segunda mitad del XVII, cuando el taller de Pedro Roldán sistematizó la producción de este tipo de obra.

\section{El belén del Museo Nacional y la cercanía estilística a Roldán}

No es mi intención rebatir la atribución realizada por diversos especialistas sobre la autoría de Luisa Roldán en relación con el extraordinario conjunto escultórico que exhibe el Museo Nacional de Escultura, en Valladolid, la llamada Cabalgata de los Reyes Magos ${ }^{42}$. Aun así no me resisto a establecer un paralelo entre esta obra y el documento que se ha analizado en este artículo. La bien 
sustentada atribución a La Roldana deriva del conocimiento de su producción y de las similitudes con otras obras. Sin embargo, hay razones de más para poner en duda esta autoría. Quiero al menos considerar algunos detalles, aunque no sean concluyentes.

De La Roldana tenemos diversas versiones de lo que habitualmente se denominaba el Portal, con la Sagrada Familia, acompañada a veces por uno o más pastores. En ningún caso los atuendos utilizados rompen con una larga tradición iconográfica, la misma que hace suya el más popular peseprenapolitano. Atuendo muy popular, casi atemporal. Ello contrasta con la Cabalgata donde todos los personajes van a la moda de la corte del tercero de los Felipe, en un anacronismo que responde a un gusto muy determinado. Esta ubicación temporal ha sido elegida de manera consciente y quizás buscada por el promotor de la obra. En ese sentido conecta bien con ciertos conceptos creativos de Roldán padre. Como hipótesis podríamos considerar que la perfección del sistema de trabajo familiar dio a la hija la talla de la familia sagrada, en tanto que el padre se ocupó del resto del belén. Y si no es propio de un artífice ya encumbrado esta labor de menudeo, quizás tenga que ver con su liderazgo al frente del taller. Por último, la referencia documental dada en este trabajo, con la constatación de la autoría roldanesca de un Nacimiento, nos descubre que el gran artífice barroco conocía este arte y sistema expresivo, y por lógica cabría pensar en el papel que jugó en la transmisión a la hija de estos modelos. Algunos estudiosos del tema validan esta hipótesis, al situar a Roldán detrás del conjunto vallisoletano, como responsable del conjunto, apreciándose su mano en algunas piezas ${ }^{43}$.

Pero quede constancia, tras lo visto, sobre este capítulo en la obra del gran maestro de la escultura barroca, y sirva como una llamada de atención sobre un capítulo importante en la producción sevillana ya en el siglo XVII.

\section{REFERENCIAS}

Ávila Vivar, Mario. "La serie de ángeles del monasterio de San José y San Roque de Aguilar de la Frontera (Córdoba)." Ucoarte. Revista de Teoría e Historia del Arte 3 (2014): 35-47. https://doi.org/10.21071/ ucoarte.v3i0.9495

Centeno, Gloria. Monasterio de Santa María de Jesús. Sevilla: Guadalquivir eds., 1996.

Fernández López, José. "Los ángeles y los arcángeles de la capilla de San Miguel de la Catedral de Jaén." Laboratorio de Arte 8 (1995): 157-173.

García Olloqui, Ma Victoria. "La iconografía de 'La Natividad' en la obra de La Roldana. El problema de los belenes atribuidos. Diferencias, estudio estilístico y opiniones cualificadas." Revista Fuentes 1 (2000).

Gestoso y Pérez, José. Ensayo de un Diccionario de los artífices qve florecieron en esta civdad de Sevilla desde el siglo XIII hasta el XVIII. Sevilla: Oficina la Andalucía Moderna, 1900.

Marcos Villán, Miguel Ángel. "La Cabalgata de los Reyes Magos: una obra singular de Luisa Roldán en el Museo Nacional de Escultura." Belén 36 (2018): 72-87.

Martínez Ripoll, Antonio. Francisco de Herrera "El Viejo". Sevilla, Excma. Diputación Provincial, 1978.

Méndez Rodríguez, Luis. Velázquez y la cultura sevillana. Sevilla: Universidad de Sevilla-Fundación FocusAbengoa, 2005.

Ortiz de Zúñiga, Diego. Anales eclesiásticos y seculares de la Muy Noble y Muy Leal ciudad de Sevilla metrópoli de Andalucía, que contienen sus más principales memorias desde el año de 1246... hasta el de 1671, ed. de Espinosa y Cárcel. Madrid: Imprenta Real, 1796. 
Palomero Páramo, Jesús Mạ. "La Platería en la Catedral de Sevilla." en La Catedral de Sevilla. Santander: Guadalquivir eds., 1985.

Quiles, Fernando. Teatro de la Gloria. El universo artístico de la Catedral de Sevilla en el Barroco. Sevilla: Diputación Provincial-Universidad Pablo de Olavide, 2007.

Romero Torres, José Luis. "Juan Pérez Crespo, escultor y padrino de la Roldana. Su trayectoria Lorca-GranadaSevilla." Laboratorio de Arte 25 (2013): 371-396.

Santos Márquez, Antonio. "Exaltación de la doctrina eucarística y de otros dogmas católicos en el Trono de Octavas de la Catedral de Sevilla. Un estudio de su iconografía." Ensayo. Historia y teoría del arte 22 (2012): 88-111.

Santos Márquez, Antonio J. "La reforma del trono de octavas de la catedral de Sevilla entre 1770 y $1772 . "$ en Estudios de platería San Eloy 2018, ed. Jesús Rivas Carmona e Ignacio J. García Zapata. Murcia: Universidad de Murcia, 2018. https://doi.org/10.6018/editum.2670

Sanz, Ma Jesús. Una hermandad gremial. San Eloy de los Plateros, 1341-1914. Sevilla: Universidad de Sevilla, 1996.

Valiña López, Francisco M. “La estética del belén napolitano.” Cuadernos de Arte 33 (2002): 107-125.

\section{APÉNDICE}

En el testamento de Acosta se hace relación de algunos bienes artísticos que no hemos detallado en el cuerpo de texto. Primero figuran diez marcos de "plata labrada", siguen treinta y seis marcos más de plata "que esta labrándose". Y luego siguen las siguientes piezas:

* Fols. 582 r/vto:

Tres rosas sortijas de diamantes (61 pesos), cinco sortijas de esmeraldas (50 p.), seis sortijas pequeñas de diamantes (26 p.), seis cintillos calados de diamantes (24 p.), dieciocho castellanos de oro en zarcillos y otras piezas quebradas (45 p.), dos hilos de perlas para garganta ( 80 p.), dos pulseros de perlas gordas (150 p.), tres hilos de perlas (30 p.), dos pulseros de perlas menudas (40 p.) // ${ }^{582 v t o}$ zarcillo de oro con tres calabazas cada uno (20 p.), ocho calabazas y cuatro botones y dos higas de oro (12 p.), dos láminas guarnecidas de oro, una de la Soledad y San Francisco de Paula, y otra una Santa Verónica, tres cruces de cristal de aresma una de caravaca guarnecida de oro y las dos lisas, una joya como una patena de cristal con un niño Jesús tallado, dos pomas de cristal, una con oro y otra ochavada, tres bolas de cristal, un rosario de coral gordo guarnecido de filigrana con su cruz y tres medallas, y un rosario de cuentas de rema guarnecido de plata y otro de calambuco guarnecido de plata y otro negro guarnecido con medallas, y otro rosario gordo de cristal, y otros dos cordas negras, otros dos y un diesmas de ambar, dos toros palilleros de laton dorados de oro molido.

* Fols. 583vto-584r:

"Yten quatro laminas las dos con la limpia concecion y otra de San Antonio de mano de Herrera con christales y laminas alrededor y guarnecidas de plata y las otras dos aliluyas con guarnicion de christales y laminas con [sic] las de arriba= dos laminas negras reliquias guarnecidas de plata $\mathrm{y}$ otras quatro laminas de Alabastro doradas los perfiles $=$ vna del nacim ${ }^{\text {to }}$ otra la adoracion de los reyes y las otras dos de Salomon= otras quatro laminas de cobre de diferentes santos.

yten un quadro del nacim ${ }^{\text {to }}$ con su moldura dorada. 
yten quatro quadros grandes vno de vn santo Christo en la Cruz otro de la trenidad y el otro de San frano de Paula y otro de señora Santa ana= Yten otros cinco quadros yguales vno de la concecion otro de la encarnacion y otro de la adoracion de los reyes y otro de San Joseph con el niño y el otro de San Joan Bautista= yten otro quatro quadros yguales uno San Geronimo San Seuastian fran ${ }^{\circ}$ y San antonio yten otros dos quadros el vno de nra Señora con el niño en los brazos y el otro de vna custodia yten otros quatro quadros con molduras la Virgen del antigua San Pedro Santo Domº y San Luis rey de francia y un quadro de la magdalena de dos varas= tres payzes y dos de prespectiuas vn quadro de nra señora de belen con moldura negra $=$ Y siete quadritos de tabla de a media vara= yten dos quadros pequeños de devociones (Santana San ${ }^{\text {mo }}$ [?] y Sto cristo)= yten vn quadro en que estan las armas de la Yglesia Yten otros dos quadros de señora Santa ana y Pedro= Yten doce quadros de angeles con las ynsinias de la pacion con sus molduras doradas-

yten vn risco en vna caja de vara y quarta de alto y vna vara de alto [sic] con su vidriera que es del nacim ${ }^{\text {to }}$ y esta echo de conchas de nacar y perlas y pastorcitos de madera.

yten un angel de madera de vna bara de alto con su peana dorado y estofado con ocho cornucopias en las manos y es nueuo y deno [sic] de Pedro roldan.

altar [margen] Vn Santo Cristo de madera cruxificado= y una ymagen de su peana de una vara con cinco angeles y dos en la luna todo dorado y estofado y en la ymagen un res- $/ /^{584 r}$ plandor en redondo de madera $=$ vn niño Jhs del mismo tamaño de la ymagen con su vandera= y vn San Joan Bautista con su cordero y vandera= y vn Santo Rey fernando de a tercia con espada y corona de plata y vn San Luis rey de francia del mismo tamaño con espada y corona de plata= yten dos remates de a media vara de madera de madera [sic] con dos aguilas encima dorado y estofado y en los pedestales ocho Santos de plata de medio reliebe $=$ yten dos relicarios de laton por dorar $=\mathrm{y}$ otros dos relicarios de laton dorados con reliquia de San lorenzo uno y otro de San Bernardino= Yten otros dos Remates de madera dorados y estofados= Yten dos altaritos de madera estofados y dorados vno de nra Señora y otra de San Joseph con sus frontales= seis macetas de a quarta las quatro y las dos mas pequeñas doradas $=$ Yten seis ramos de talco y piedras las dos para los macetas $=$ otros seis ramos de seda los quatro usados y dos nueuos= dos macetas de flores de raso con maceticas de plata $=$ dos quadritos con guarniciones de plata el uno de Santo Cristo a la Coluna de laton dorado de molido [?] y el otro una concecion de marfil.

yten vn anus de asabache rodeado de obalos con reliquias y rem ${ }^{\text {tes }}$ de plata y la adorazion de los reyes en medio quatro macetitas de laton doradas de oro de molido quatro peanas de madera doradas y estofadas= Yten tres frontalitos de carey y Piedras y Plata guarnecidas $=$ Yten dos tronos de organo con dos angeles uno alsando los fuelles y otro tocando y otros dos cantando y en el otro trono con ynstrumentos de ministriles y su facistol en medio todo dorado y estofado= dos angeles de madera de mano de Roldan de a media vara con sus cornicopias [sic] dorados y estofados.

nacim $^{\text {to }}$ [margen] Vn sol de rayos y en medio el padre eterno que sera de tres quartas de en rredondo y de madera dorado y esfofado de mano de Pedro roldan.

Yten el portal con el niño la Ymagen de nra Señora y San Joseph y un angel y un pastor viejo todo de madera dorado y estofado= Yten doce angelitos de madera $/ /^{584 \mathrm{vto}}$ boladores encarnados y las alas Estofadas= Y otros quatro mas pequeños del mismo Género.

Yten los tres reyes con sus caballos de madera dorados y estofados de mano de roldan dos figuras aposentador y trompeteros en sus cauallos de madera dorados y estofados de mano de roldan= ochos criados para los reyes con sus libreas de mano de roldan= yten sus acemilas con sus cofres de carey con sus cubiertas de terciopelo y puntas de plata= yten tres criados de las azemilas los dos de 
madera y uno de barro = Yten vn angel de madera de la gloria estofado y dorado de mano de roldan= yten otros quatro angeles de madera con ynstrumentos en las manos estofados y dorados de mano de roldan Yten seis pastorictos de graecio [ $¿$ a tercia?] y vn negro y vna negra y dos matachines todo de madera dorados y estofados y ten quatro angeles de madera de a tercia con sus peanas estofadas y doradas.

otro nacim $^{\text {to }}$ [margen] Yten una ymagen sentada con el niño en brazos y San Joseph con su cayado todo de madera dorado y estofado y su portal de madera= yten los tres reyes y otros dos de a cauallo todo ello dorado y estofado.

Yten diez y ocho pastores y pastoras y de diferentes trages pintados= Vna dozena de obejas de madera de todas echuras todo de mano de Blas muños

Yten diez y seis obejas de barro cosido y siete puercos y una parida y doze toros de barro cocido= y dos pastores viejo e vieja de varro cozido y ten quatro toros de madera y tres pilas de oja de lata y un molino de lo mismo= yten vna ciudad de madera de vara y media de largo= vna choza y pedreria por de dentro una torre de madera de echura de la Santa ygelsia estofada y dorada con su jiraldillo y canpanas de plata $=$ ocho vancos $\mathrm{y}$ veinte tablas sobre que se pone el nacim ${ }^{\text {to }}=$ vn lanzo quadrado Pintado el cielo y de cabezas de serafines que serbia para el cielo del nacim ${ }^{\text {to }} \mathrm{y}$ otros dos lienzos de a tres varas cada vna semejantes al de arriba.

yten vn quadro de madera con tres nichos donde esta un San Josph con el niño y encima $/ /^{585 r}$ un San Joan Baupp ${ }^{\mathrm{a}}$ y en el ultimo nicho vn niño Jph y a los lados San fran ${ }^{0}$ y San antonio con su frontal y colunas todo ello dorado y estofado con su caja de madera Pintada en que se guarda.

Yten otro Portal de nacim ${ }^{\text {to }}$ con quatro pilares y techo todo dorado y estofado con su caja de madera donde se guarda y en las ptas de la caja Santos pintados y vna ymagen de nra Señora y vn San Joseph con dos vestidos de tela y vn niño Jhs de pasta que esta en los brazos de la ymagen."

Concluye con frontales y colgaduras. Y con dos docenas y media de ángeles de pasta de una tercia, todos iguales, y dieciséis Apóstoles de pasta, medios cuerpos.

Notas

1 Archivo Histórico Provincial de Sevilla [AHPS], lib. 12999, fols. 579-587r., 26-VIII-1674. Hizo un primer testamento el 25 de marzo de 1666. En éste hacen declaración conjunta el artífice con su esposa, María de Gálvez. AHPS, lib. 12975, fol. 855; 1666-III-25.

2 El mismo que figura en la relación de febrero de 1622 de plateros de plata. Sanz, Una hermandad gremial, 148.

3 Méndez Rodríguez, Velázquez y la cultura sevillana, 161-162.

4 Idem. fol. 579vto.

5 Idem. fol. 580 or

6 Tenía a la sazón cuatro años. Y curiosamente años más tarde se hacer acreedora de una de las dotes que daba el gremio a sus huérfanos pobre. Sanz, Una hermandad gremial, 161.

7 Idem, 581r

8 AHPS, lib. 12985, fol. 251-253; 18-V-1669.

9 AHPS, lib. 12998, fols. 254-256; 24-I-1674. Todos los que confluyen en este documento son plateros, incluso uno de los testigos, Gaspar Romero, que lo era de mazonería. Y es posible que el padre de la contrayente también lo fuera. Los padres del esposo son de Madrid.

10 AHPS, lib. 12986, fol. 135; 31-VIII-1669.

11 Gestoso y Pérez, Ensayo de un Diccionario I, 200. Dedicó gran parte de su periodo a la renovación de la plata vieja. Quiles, Teatro de la Gloria, 362.

12 Lo que en 1681 se tasaba en cuatro pesos por marco labrado. Quiles, Teatro de la Gloria, 359. 

de la Gloria, 362.

14 Según la documentación publicada por Palomero Páramo, "La Platería en la Catedral de Sevilla," 612.

15 Acuerdo capitular de mayo de 1669. Quiles, Teatro de la Gloria, 136.

16 Santos Márquez, "La reforma del trono de octavas de la catedral de Sevilla entre 1770 y 1772," 510. Del mismo, "Exaltación de la doctrina eucarística", 88-111.

17 La discusión sobre la forma que habría de adoptar la pieza giró en torno a "un pedestal", "un frontal" o lo que finalmente se eligió "un trono". Al aceptar el encargo, en 1672, se caracteriza la obra como "una peana-urna para el biso chico", vinculada con lo que se denominaría "la mesa de los Angeles en las octauas que esta descubierto $\mathrm{n}^{\text {ro }} \mathrm{s}^{\mathrm{r}}$ Sacramentado". Bernardo Simón de Pineda haría el basamento de madera. Quiles, Teatro de la Gloria, 139. 18 AHPS, lib. 3691, fol. 650; 3-XII-1655.

19 No es seguro que sea el mismo individuo que desde abril de 1647 , y posiblemente hasta su muerte, ejerciera como despensero del arzobispo Agustín Spínola. AHPS, lib. 1792, fols. 908-909; 27-IV-1647.

20 Ortiz de Zúñiga alude al estado de postración en que se encuentra Núñez de Sepúlveda y su deseo de celebrar la Inmaculada Concepción con tan notable fundación. Ortiz de Zúñiga, Anales eclesiásticos V, 109; año 1656.

21 Gestoso, Ensayo de un Diccionario, 127.

22 AHPS, lib. 12958, fols. 31-32; 3-l-1660. Los demás cargos del oficio eran Miguel de la Cuesta (padre mayor), Martín de Echegoian (escribano) y otros artistas, a saber: Mateo Gutiérrez, Juan del Castillo, Gregorio de Cubas, Bartolomé Ribero, José Alfonso y Juan Vítor de Pinar.

23 Quiles, Teatro de la Gloria, 275.

24 Cuatro marcos "q de su casa entregó" al citado. Archivo de la Catedral de Sevilla [ACS], Fábricas, lib. 4537, fol. $32 r$.

25 AHPS, lib. 12939, fol. 400, 9-IX-1654.

26 ACS, Sec IV, lib. 4537 (518). Cuentas de Particulares de Fábricas. 1665-1768, fols. 34V-35r.

27 ACS, Sec. IV, lib. 4537 (518), fols. 73v.

28 Romero Torres, "Juan Pérez Crespo," 381.

29 Abajo, en el apéndice se incluye una relación de piezas tasadas

30 AHPS, lib. 12939, fols. 581vto y 582 r.

31 Martínez Ripoll, Francisco de Herrera "El Viejo", 248-249.

32 Una muestra muy interesante es la que guarda el monasterio de San José y San Roque, en Aguilar de la Frontera. Ávila Vivar, "La serie de ángeles del monasterio," 35-47. Valga también el estudio de Fernández López, "Los ángeles y los arcángeles," 157-173.

33 Ibid.

34 "Tal vez, también haya en este "Nacimiento", claramente sevillano, cierto recuerdo de la escultura granadina, presente en muchas de las obras de La Roldana a las que se lo transmitió su padre y maestro Pedro Roldán García Olloqui. "La iconografía de 'La Natividad'" (consultado en junio de 2019). Gloria Centeno atribuye a Roldán otro belén que pertenece a la comunidad franciscana. Centeno, Monasterio de Santa María de Jesús, 120.

Revista Fuentes, 1 (2000); consultado en junio de 2019.

36 Valiña López, "La estética del belén napolitano," 107-125.

37 APNS., of. 23, 1708, fol. 705; inventario del 10 de noviembre.

38 ACS, Sec. I, AA CC, leg. 95, 1717-1718, fol. 138vto. 11-XI-1718.

39 Obligación de entrega de botijas de vino a un marchante del Puerto de Santa María. AHPS, lib. 12970, fol. 834; 1664. También recordemos a Domingo de Leras, trianero, que debía entregar barro a Alonso Martín Orejuela, fabricante de ladrillo. AHPS, lib. 11857, fol. 907; 1653.

40 Carta de pago dada a Alonso de Ortega, mayordomo de propios y rentas de la ciudad, de 2700 reales, por la obligación firmada con la ciudad, cabildo y regimiento, para la fiesta del Corpus. AHPS, lib. 11854., fol. 979; 7V-1652.

41 Borrelli, citado por Valiñas, "La estética del belén napolitano," 110.

42 Su ingreso en el Museo suscitó enorme espectación. Vid. Marcos Villán, "La Cabalgata de los Reyes Magos," $72-87$.

43 Salida de la gubia paterna en opinión de Lorenzo Alonso de la Sierra y Pablo Amador Marrero, a quienes agradezco su apoyo en la elaboración de este texto y sobre todo en la asunción de esta idea. 